\title{
Does Hope Mediate and Moderate the Relationship between Happiness Aversion and Depressive Symptoms?
}

\author{
Rebecca A. Bloore ${ }^{1 *}{ }^{(}$, Paul E. Jose1, Mohsen Joshanloo² \\ ${ }^{1}$ Victoria University of Wellington, Wellington, New Zealand \\ ${ }^{2}$ Keimung University, Daegu, South Korea \\ Email: ^becky.bloore@yahoo.co.uk
}

How to cite this paper: Bloore, R. A., Jose, P. E., \& Joshanloo, M. (2020). Does Hope Mediate and Moderate the Relationship between Happiness Aversion and Depressive Symptoms? Open Journal of Depression, 9, 1-16.

https://doi.org/10.4236/ojd.2020.91001

Received: December 23, 2019

Accepted: January 18, 2020

Published: January 21, 2020

Copyright $\odot 2020$ by author(s) and Scientific Research Publishing Inc. This work is licensed under the Creative Commons Attribution International License (CC BY 4.0).

http://creativecommons.org/licenses/by/4.0/

\begin{abstract}
The literature is beginning to document how and for whom "fear of happiness" (happiness aversion, i.e. the expectation that being happy can have negative consequences) is predictive of psychological outcomes. We sought to determine whether hope, an important protective factor against depressive symptoms, might mediate and moderate the relationship between happiness aversion and depression. In a dataset of 588 undergraduate psychology students, evidence was found that hope functioned as a mediator as well as a buffer in the relationship between happiness aversion and depression. In addition, exploratory analysis of a small longitudinal dataset $(\mathrm{N}=74)$ suggested that hope also played the same roles in the relationship between fear of happiness and depression over time. These findings suggest that interventions that create hope can be effective in disrupting the relationship between happiness aversion and depressive symptoms.
\end{abstract}

\section{Keywords}

Hope, Depression, Happiness Aversion, Depressive Symptoms, Mediation, Moderation

\section{Introduction}

The search for happiness seems to be a fundamental goal of human beings, with Aristotle arguing in $350 \mathrm{BC}$ that happiness is a central component in the meaning and purpose of life (Aristotle, 1955). Two millenia later, it seems that most individuals continue to desire to obtain happiness, and in capitalistic countries this urge is often manifested as a desire to engage in higher levels of consump- 
tion in order to increase personal levels of happiness (Jansson-Boyd, 2010). Self-help books designed to facilitate and aid in the search for happiness are readily available for purchase (Chernoff \& Chernoff, 2018). It is additionally regarded by many people as one, if not the most, basic goal of existence (Layard, 2011), and to that end many individuals strive for happiness in their everyday experiences (Joshanloo, 2013).

Being happy is nearly always identified as one of the most important values in an individual's life, with most people around the globe expressing that they want to experience more happiness (Diener, 2000; Layard, 2011). There is also a wide-spread perception that individuals are accountable for their own individual levels of happiness (Benjamin, Heffetz, Kimball, \& Rees-Jones, 2012; Rubin, 2009). As a consequence, those individuals who experience difficulty in feeling happy are at risk of believing that there must something wrong with them, fuelling feelings of inadequacy and depression (Gilbert et al., 2012). Although some people try to achieve a constant mood of happiness, some people believe that a state of continuous happiness is undesirable or unachievable (Joshanloo \& Weijers, 2014). Seeking a consistent level of high positive affect and low negative affect seems to be somewhat unrealistic; however the degree to which people strive for increased happiness indicates that the desire to obtain this unrealistic sense of well-being is prominent within Western society (Horwitz \& Wakefield, 2007).

\section{Happiness Aversion}

In contrast to this wide-spread attraction to happiness, over the last few years it has been noted that not all individuals strive for high levels of subjective happiness, and, in fact, some people may seek to avoid happy mood states (Agbo \& Ngwu, 2017; Joshanloo, 2018). The presumed innate drive for hedonic pleasure is now being questioned by research that demonstrates that individuals may not always seek out positive emotions, and in some instances may avoid individual happiness (Joshanloo, 2018). In an extensive literature review, Joshanloo and Weijers (2014) have highlighted how some individuals believe that happiness eventually will result in negative mood states such as sadness, suffering, or even early mortality. They noted that the reluctance towards seeking individual happiness could also be due to internal beliefs that being happy is sinful or unnecessary, particularly in non-Western cultures where collective happiness is more sought after than individual happiness (Joshanloo et al., 2014). An example of this happiness aversion stance could be the observed "taboo on pleasure" that Arieti and Bemporad (1980) have previously documented, describing depressed individuals' tendency to associate positive emotions with negative outcomes. Indeed researchers have previously noted that major depressive disorder sufferers often report an inability to derive pleasure from previous pleasurable pursuits (Dichter, 2010).

As a consequence, a small, but growing segment of the literature has been produced on the topic of "fear of happiness", as it is sometimes termed. The 
term "fear of happiness" is usually operationally defined as an aversion to happiness due to the belief that happiness may cause something bad to happen (Joshanloo, 2013). Joshanloo (2013) has created and tested a 5-item self-report scale designed to measure happiness aversion. The scale has been examined cross-culturally with data collected from 14 different nationalities and although happiness aversion was demonstrated to be more prevalent in non-Western cultures, a substantial number of people residing within Western cultures (e.g. New Zealand, the site of the present study) also report relatively high levels as well. In addition, Gilbert and colleagues (2012) have created a 9-item happiness aversion scale that captures various motives for avoiding happiness as well.

Investigations into the validity of happiness aversion measures and their correlates are necessary as the scores from these scales have been documented to show a positive association with depression (Gilbert et al. 2012). Several other studies have also shown that individuals reporting high levels of happiness aversion reported lower subjective well-being and satisfaction with life (Joshanloo, 2013; Joshanloo et al., 2014). Moreover, happiness aversion has been positively linked to neuroticism, a personality trait that is strongly associated with depression and anxiety (Rovner \& Casten, 2001). What is unknown at present is the effect that other psychological dynamics may play in mediating and moderating the strength of the demonstrated relationship between happiness aversion and negative outcomes such as depression. Thus, in the present study we sought to test whether hope might function as a mediator between happiness aversion and depression, and we also sought to determine whether hope might moderate (i.e. buffer) the relationship between happiness aversion and depression.

\subsection{The Relationships among Hope, Depression, and Happiness Aversion}

Literature argues and shows that positive human strengths such as courage, hope and optimism have a diminishing influence on psychological disorders (Seligman \& Csikzentmihalyi, 2000; Peterson, 2000). Hope, especially, has been identified as a positive trait that can contribute to happiness, health and perseverance (Peterson, 2000). The construct of hope is consistently identified as an important facet of psychological well-being and has elicited considerable attention from scholars (e.g. Mathew, Dunning, Coats, \& Whelan, 2014). Individuals who report high levels of hope have been shown to experience fewer depressive symptoms during times of stress (Arnau, Rosen, Finch, Rhudy, \& Fortunato, 2007). Snyder (2000) has defined hope as a positive motivational state that is founded on a sense of successful goal-directed behaviour whereby an individual is confident in his or her ability to implement plans to accomplish his or her goals (agency) and in finding alternative ways to accomplish them (pathways). Hope is known to play a protective role against acquiring depressive thoughts, attitudes, and mood states, and a negative relationship between hope and depression is consistently reported (Feldman \& Snyder, 2005). Hope has not only been identi- 
fied as being negatively related to general maladjustment and suicidal thoughts, it has additionally been directly (negatively) linked to depression (Chang \& Sanna, 2003; Du, King, \& Chu, 2016).

Protective characteristics such as hope have been shown to moderate relationships between maladaptive factors and depression. For instance, hope has been demonstrated to attenuate the relationship between negative life events and greater levels of depressive symptoms (Visser, Loess, Jeglic, \& Hirsch, 2013). In a similar vein, Geiger and Kwon (2010) found evidence for hope moderating the relationship between rumination and depression. Hope was a significant moderator for both brooding and reflecting subtypes of rumination, further highlighting the protective nature of hope in regards to depression.

The relationship between hope and depression has additionally been previously explored in mediation analysis, whereby hope was shown to have both direct and indirect negative effects on depressive symptoms (Chang \& Sanna, 2003). In particular, Hopelessness Theory, a prominent theory in the depression literature, posits that lack of hope is associated with greater depression (Abramson, Metalsky, \& Alloy, 1989). Accordingly we suggest that happiness aversion is likely to be negatively associated with low levels of hope, because when positive emotions and happiness that accompany and predict desired life outcomes are devalued, a person's aspirations to engage in activities will likely be diminished. This prediction is compatible with theories such as subjective utility theory (Quiggin, 1982) and expectancy-value theory (Wigfield \& Eccles, 2000) in that these theories posit that the strength of people's motivational commitment to life choices depends in part on their expectations of the likelihood that positive hedonic outcomes will be experienced (Higgins, 2011).

Although not explicitly documented, prior empirical research suggests that happiness aversion is likely to be associated with lower levels of hope, for example, Joshanloo et al. (2015) have documented that happiness aversion was negatively correlated with a person's purposeful involvement in the process of personal growth. They also found that happiness aversion was correlated with fate control (i.e. happiness aversion was associated with beliefs that important outcomes in life are fated, unpredictable, and unalterable). These findings highlight hope as a protective factor against depression and suggest that individuals who report high levels of hope may report lower levels of depressive mood states. In sum, we predicted that happiness aversion would be negatively predictive of hope, and hope, in turn, would be negatively predictive of depressive symptoms, consistent with a mediational relationship.

\subsection{Aims and Hypotheses}

The main goal of the current research was to discover new information about the relationships among happiness aversion, hope, and depressive symptoms, and determine whether hope plays a buffering and/or mediating role in the relationship between the fear of happiness and depression. The mediation hypothe- 
sis tests whether happiness aversion predicts higher depressive symptoms through the mechanism of lowered hope, and the moderation hypothesis examines the possibility that the relationship between happiness aversion and depressive symptoms might be attenuated for individuals who report high levels of hope (for an example of side-by-side mediation and moderation analyses of a single dataset see Jose \& Huntsinger, 2005).

Our first prediction was that happiness aversion would negatively predict hope, and hope, in turn, would negatively predict depressive symptoms. The second hypothesis was that hope would function as a buffer of the relationship between happiness aversion and depressive symptoms. Additional to these cross-sectional analyses, we posed a research question as to the nature of relationships between happiness aversion and hope across time with a small exploratory two-wave longitudinal sample $(\mathrm{N}=74)$. We sought to obtain preliminary evidence that the posed mediation and moderation hypotheses would be supported with longitudinal data.

\section{Method}

\subsection{Participants}

Individuals were recruited from a mid-sized university in New Zealand as part of a data collection exercise within an undergraduate Psychology course. The only inclusion criterion was being a student in the course, and no one was excluded from participating. In order to test our hypotheses, data were obtained from two courses (collected three months apart). In Dataset 1, a total of 337 undergraduate psychology students enrolled in a second year course were invited to complete a survey measuring a range of topics such as personality, positive and negative mood states, and interpersonal styles. The sample consisted of 80 males and 257 females, which is a typical gender ratio among undergraduate psychology majors but not typical of undergraduate students. Age was sampled within age-bands in order to enable anonymity (the dataset was made available to the class for practice in data analysis). Due to ethical reasons (i.e. the dataset was made available to all students in the class) we avoided collecting personally identifying demographic information, and thus age was reported in bands. The sample was composed of 17818 - 19 year-olds, 12720 - 25-year-olds, 1626 - 30-year-olds, and 19 individuals were older than 30 years. The large majority of participants identified as European New Zealander (about 90\%), and small numbers of Maori, Pacific Islander, and Asian New Zealanders were included as well. European New Zealanders were overrepresented compared to New Zealand census frequencies, although the percentage was typical for tertiary students in New Zealand. In Dataset 2, 249 undergraduate psychology students enrolled in a compulsory third year course completed the same survey. The sample included a total of 55 males and 191 females ( 3 did not provide gender information); 10718 19 year-olds, 10120 - 25-year-olds, 3626 - 30-year-olds, and 5 individuals were older than 30 years. Since these two datasets were very similar, we combined 
them into a single cross-sectional dataset in order to make analyses simpler.

Since a few students who take the first course go on to take the second course in the second term of the same year, we linked the datasets and found that 74 individuals had completed the survey at both time points, enabling us to test an exploratory research question with a small longitudinal sample in addition to the two concurrent datasets. The size of the concurrent dataset afforded the assessment of medium effect sizes, whereas the size of the longitudinal sample would allow identification of a large effect size $\left(f^{2} s>.15\right.$ and .35 respectively, Cohen 1992). Ethical approval was granted by the sponsoring university, participation was voluntary, and signed informed consent was collected from all participants.

\subsection{Measures and Procedure}

1) Depressive symptoms. In order to assess levels of depressive symptoms, a shortened version of the Centre for Epidemiological Studies Depression scale (CES-D; Radloff, 1977) was administrated to participants. Although the original scale consists of 20 items, due to space and time limitations, 9 highly loading items were used in the present case. Participants were presented with items such as "I got upset by things that don't usually upset me" and "I could not stop feeling bad, even when others tried to cheer me up". Participants indicated on a 4-point Likert scale how often (in the last week) they experienced the particular mood state. Responses ranged from Less than one day (1) to 5 - 7 days (4). The scale has previously demonstrated good internal reliability, with Cronbach's alphas typically reported from .85 to .90 (e.g. Al-Modallal, Abuidhail, Sowan, \& Al-Rawashdeh, 2010). The concurrent dataset also yielded a Cronbach's alpha within that range, namely .88 .

2) Happiness aversion. To measure happiness aversion, a recently developed 5-item "fear of happiness" scale (FHS; Joshanloo, 2013) was administrated to participants. Items address the central concept of the fear of happiness, which is the belief that happiness or positive events should be avoided because they can sometimes lead to negative emotions or events. Two sample items are: "I prefer not to be too joyful because usually joy is followed by sadness", and "Excessive joy has some bad consequences". Each item is rated on a 7-point Likert scale ranging from strongly agree (1) to strongly disagree (7). This scale has yielded good internal reliability and demonstrated good validity in previous literature (Joshanloo, 2013). The concurrent dataset yielded a Cronbach's alpha of .88. For the longitudinal data, a Cronbach's alpha of .90 was obtained for the Fear of happiness scale at both time points.

3) Hope. A shortened version of The Adult Hope Scale (AHS) that included 8 items based on the original 12 items was administrated to participants to assess levels of hope (Snyder et al., 1991). Examples of items are: "I energetically pursue my goals" and "There are lots of ways around any problem". Participants respond to each item within the scale by using a 4-point Likert scale ranging from 
definitely false (1) to definitely true (4). Previous research has reported good reliability and validity for the AHS (Snyder, 2000). In the current study, the Cronbach's alpha for the concurrent dataset was .87. For the longitudinal dataset, a Cronbach's alpha of .89 was obtained at Time 1 and .90 at Time 2.

\subsection{Analytic Procedures}

Missing values constituted less than $1 \%$ of the dataset and Little's test for MCAR demonstrated that they were missing completely at random. Expectation-Maximization (EM) imputation (Lin, 2010) on this small amount of missing data was conducted to maximise power. As these datasets were collected around three months apart from samples that were similar, they were combined before concurrent analyses took place. The total concurrent dataset included 588 individuals.

The first step in the mediation and moderation analysis was to test the nature of the basic relationship between the independent variable of happiness aversion and the dependent variable of depressive symptoms (for a description of this method, see Jose, 2013a). For the mediation analysis, we then interposed hope between the IV and the DV to determine whether significant mediation could be obtained. For the moderation analysis, we performed the standard moderation analysis (Jose, 2013a), and then examined simple slopes to examine how different levels of hope yielded different slopes in the relationship between happiness aversion and depression. And last, we conducted both a longitudinal mediation and a longitudinal moderation (Jose, 2013a) using the longitudinal dataset to provide elucidation for the research question.

\section{Results}

\subsection{Descriptive Statistics}

Presented in Table 1 are the means and standard deviations for the combined dataset. Consistent with the literature, happiness aversion demonstrated a moderate positive correlation with depression. Also consistent with expectations, moderate negative associations were found between hope and the other two measures.

\subsection{Concurrent Mediation: Did Hope Mediate the Relationship between Happiness Aversion and Depression?}

Using AMOS (Arbuckle, 2013), a path model was constructed whereby the

Table 1. The bivariate correlations and descriptive statistics for happiness aversion, hope, and depression in the concurrent dataset.

\begin{tabular}{ccccc}
\hline & Hap Aversion & Hope & Depression & Means and SDs \\
\hline Hap Aversion & - & & & $2.38(1.23)$ \\
Hope & $-.39^{* * *}$ & - & $3.04(.67)$ \\
Depression & $.37^{* *}$ & $-.41^{* * *}$ & - & $1.90(.67)$ \\
\hline
\end{tabular}

Note: Hap Aversion $=$ Happiness Aversion. $p<.05 ;{ }^{* *} p<.01 ;{ }^{* *} p<.001 . \mathrm{N}=588$. 
exogenous variable was the happiness aversion variable, hope was the mediating variable, and depression was the dependent variable. The a path was the relationship from happiness aversion to hope, and the $b$ path was the relationship from hope to depression. Our hypothesis stipulated that the basic relationship between happiness aversion and depression would be mediated by hope. This proposal was tested with a bootstrapped mediation analysis. The size of the indirect effect was estimated with a $95 \%$ bias-corrected confidence interval computed on the basis of 5000 bootstrapped iterations. Evidence was found to support the hypothesised mediation relationship, $a \times b=.09$, se $=.001,95 \% \mathrm{CI}=$ $[.060, .122], p<.001$. The statistically significant indirect effect, consistent with Hypothesis 1, suggests that happiness aversion predicted a diminishment of hope, which, in turn, predicted higher levels of depression. In other words, fear of happiness predicted higher depression through the mechanism of lower levels of hope.

\subsection{Concurrent Moderation Analysis: Did Hope Moderate the Relationship between Happiness Aversion and Depression?}

A moderation analysis was performed whereby the independent variable was happiness aversion, hope was the moderating variable, and depressive symptoms was the dependent variable. A hierarchical regression was computed with three steps. In the first step, the covariates of gender and age were entered. Aversion to happiness and hope were included in the second step, followed by the interaction term between happiness aversion and hope entered on the third step. In the case of significant moderation, the results are graphed and simple slopes are examined to determine how the moderator influenced the basic relationship.

On the first step, we determined that neither age nor gender significantly predicted depressive symptoms, $p s=.65$ and .48 respectively $\left(R^{2} c h=.002, p=.72\right)$. On the second step, both happiness aversion $(\beta=.25, p<.001)$ and hope $(\beta=$ $-.31, p<.001)$ significantly predicted depressive symptoms $\left(R^{2} c h=.22, p<.001\right)$. As expected, happiness aversion positively predicted, and hope negatively predicted, levels of depressive symptoms.

And finally, the interaction term was found to be a significant predictor on the third step, $\beta=-.57, p=.003, R^{2} c h=.012$. In order to interpret this result, we graphed the result with ModGraph (Jose, 2013b), and the result is depicted in Figure 1. The figure shows, consistent with Hypothesis 2, that hope functioned as a buffer of the happiness aversion to depression relationship. Although simple slopes analyses indicated that all slopes were significant at $p<.001$, the flattest slope was generated by the high hope group, signifying the presence of a buffer (Jose, 2013a).

\subsection{Exploratory Analyses with the Longitudinal Dataset}

In order to investigate in an exploratory fashion whether the two significant findings with the concurrent dataset could be extended to the longitudinal context, we explored our research question: would we find a significant longitudinal 


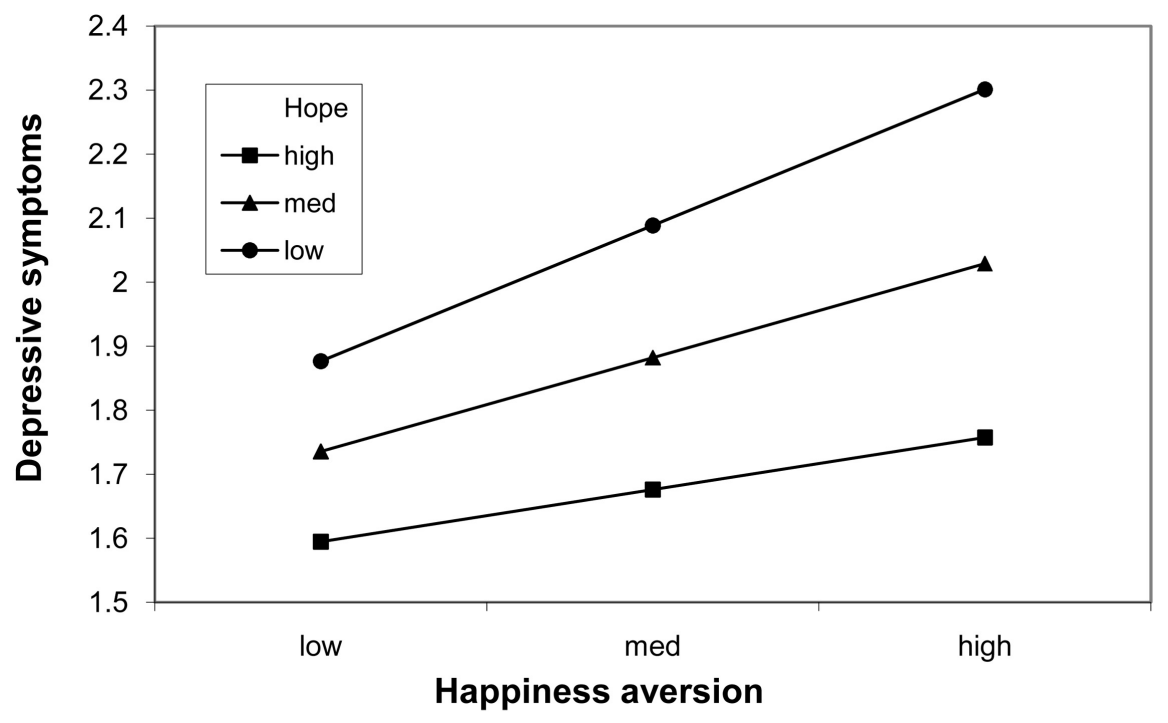

Figure 1. Graphical depiction of the moderating effect of hope on the relationship between happiness aversion and depression with the concurrent dataset.

mediation and a significant longitudinal moderation in our small longitudinal sample?

1) Longitudinal mediation. We first investigated the ability of hope to mediate the influence of fear of happiness on depression over time with a bootstrapped two-wave longitudinal mediation analysis (Jose, 2013a) (see Figure 2; for descriptive statistics, see Table 2). This exploratory analysis was performed because mediation results with concurrent datasets are not always replicated in longitudinal datasets (Jose, 2013a, 2016; Maxwell \& Cole, 2007). Despite the small sample size of the current longitudinal dataset, statistical evidence supported the concurrent mediation finding, namely that hope would function as a mediator longitudinally, $a \times b=.023$, se $=.016,95 \% \mathrm{CI}=[.001, .070], p=.039$, indirect/total effect size $=27 \%$. This exploratory analysis provided tentative evidence that the concurrent mediation result could be confirmed within a longitudinal context.

2) Longitudinal moderation. We next investigated the ability of hope to moderate the influence of fear of happiness on depression over time with a two-wave longitudinal moderation analysis (Jose, 2013a) (see Figure 3). Although not frequently performed, "the point of doing this type of analysis is that one can see whether the IV and ModV separately and together predict change in a DV" (Jose, 2013a: p. 211). The statistical analysis yielded a statistically significant longitudinal moderation term, $\beta=-1.25, R^{2} c h=.06, p=.017$. The result was graphed with ModGraph (see Figure 4) and the simple slopes analysis showed that the only significant slope was manifested by individuals reporting low levels of hope (SS $=.20, p=036$ ). Thus, the finding obtained with a longitudinal moderation result was consistent with the concurrent moderation result. Although both analyses showed that hope buffered the happiness aversion to depressive symptoms relationship, the latter finding provided tentative evidence 


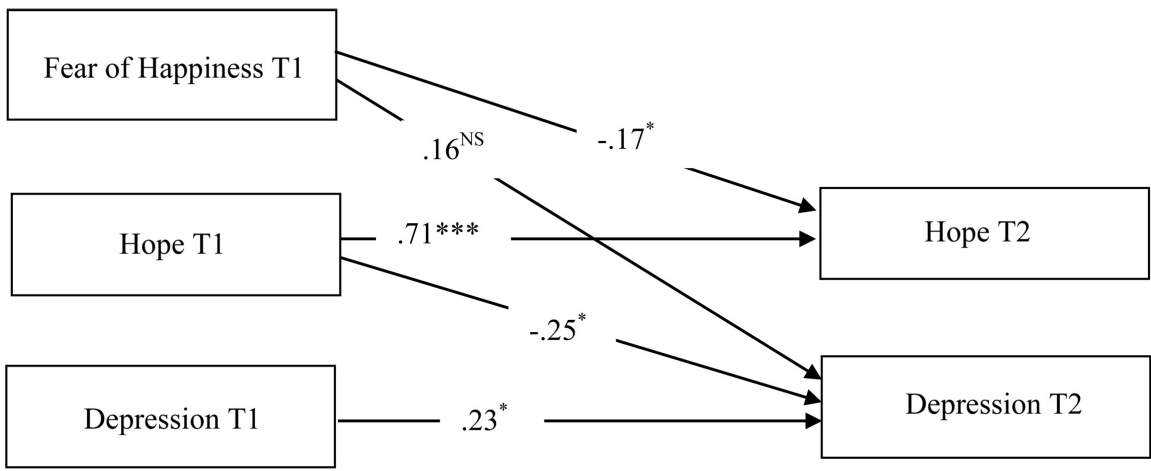

Figure 2. Longitudinal mediation of hope between happiness aversion T1 to depression T2. Note. ${ }^{\star} p<.05 ; p<.001$. Numerical values are standardized regression coefficients. Not depicted to ease comprehension are covariances among the three exogeneous variables and between the error terms of the two endogenous variables.

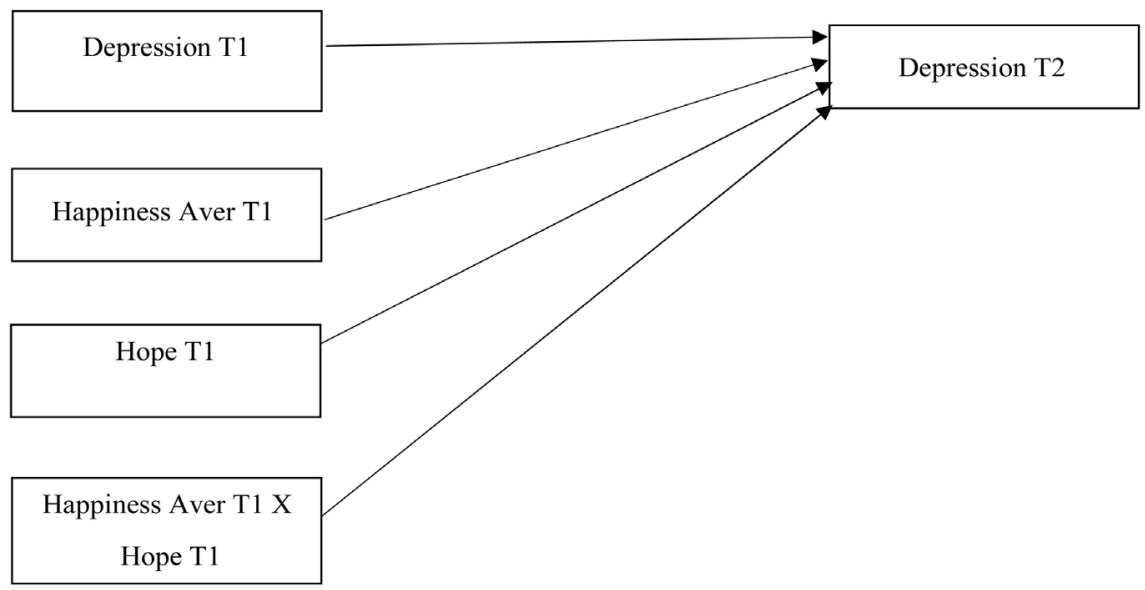

Figure 3. Model depicting longitudinal moderation of hope of the happiness aversion T1 to depression T2 relationship.

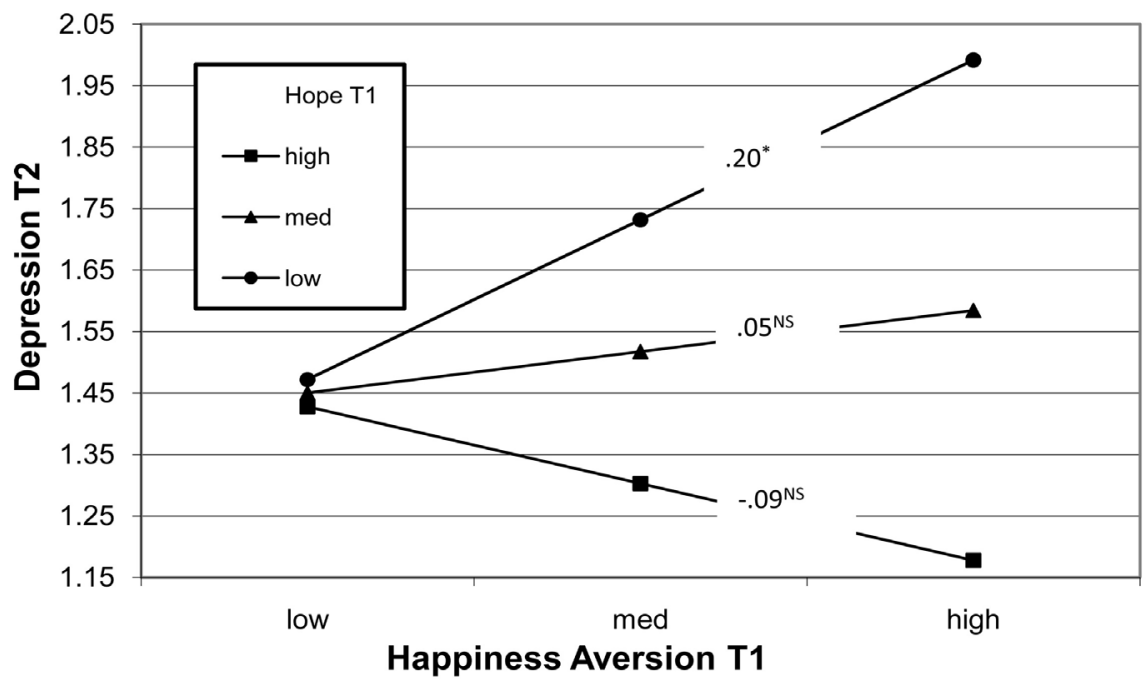

Figure 4. ModGraph depiction of longitudinal moderation by hope of the relationship between happiness aversion T1 to depression T2 with simple slopes. Note. NS = non-significant; ${ }^{\star} p<.05$. 
Table 2. The bivariate correlations and descriptive statistics for happiness aversion, hope, and depression at times 1 and 2 in the longitudinal sample.

\begin{tabular}{ccccccc}
\hline & Happiness & Hope & Hope & Depression & Depression & Mean (SD) \\
& Aver T2 & T1 & T2 & T1 & T2 & . \\
\hline Happiness & $.65^{* * *}$ & $-.42^{* * *}$ & $-.47^{* * *}$ & $.36^{* *}$ & $.34^{* *}$ & $2.45(1.33)$ \\
Aver T1 & & & & & & \\
Happiness & & $-.26^{*}$ & $-.41^{* * *}$ & $.24^{* * *}$ & $.30^{* *}$ & $2.48(1.27)$ \\
Aver T2 & & & $.78^{* * *}$ & $-.45^{* * *}$ & $-.42^{* * *}$ & $3.02(.53)$ \\
Hope T1 & & & $-.34^{* *}$ & $-.45^{* * *}$ & $3.02(.50)$ \\
Hope T2 & & & & $.39^{* * *}$ & $2.02(.75)$ \\
Depression T1 & & & & & $1.95(.77)$ \\
Depression T2 & & & & & & \\
\hline
\end{tabular}

Note: ${ }^{*} p<.05 ;{ }^{* *} p<.01 ;{ }^{* * *} p<.001 . \mathrm{N}=74$. Happiness Aver $=$ happiness aversion.

that hope buffered the prediction by happiness aversion of depressive symptoms over time.

\section{Discussion}

In this study we sought to identify in a large dataset whether hope would both mediate and moderate the relationship between happiness aversion and depression. We additionally carried out preliminary analyses on a small longitudinal sample to examine the same relationships over time. Support was obtained for the hypothesis that hope would mediate the relationship between fear of happiness and depressive symptoms. Specifically, the significant indirect effect suggested that fear of happiness predicted lower hope, and this attenuated hope, in turn, was predictive of higher levels of depressive symptoms. Hope also attenuated the strength of the relationship between happiness aversion and depressive symptoms in the moderation analyses, both concurrently and longitudinally. These results replicated the previously reported concurrent relationship between happiness aversion and depressive symptoms (Gilbert et al., 2012), i.e. happiness aversion was found to be significantly and positively associated with depressive symptoms. Furthermore, this study contributes new information to the literature by verifying that hope functions as both a moderator and a mediator between happiness aversion and depressive symptoms, i.e. identifying a mechanism by which a third variable, hope, mediates between happiness aversion and depressive symptoms, and also documenting that the same third variable, hope, has the capacity to disrupt or buffer this basic relationship.

To date one empirical research paper has linked happiness aversion with depressive symptoms (i.e. Gilbert et al., 2012), albeit with a concurrent dataset. This paper constitutes an innovative way of exploring happiness aversion and depression in that it is the first study of its kind to examine the role of trait hope within the happiness aversion to depression relationship. The present research effort contributes to the small, but growing research on happiness aversion, supporting the prediction that happiness aversion would predict increased depressive symptoms (as suggested by Gilbert et al., 2012). However, our findings 
additionally and innovatively provide an extension to this basic hypothesis, suggesting one way how happiness aversion predicts increased depressive symptoms over time, namely that happiness aversion seems to predict greater depressive symptoms through the mechanism of diminished hope. Hope also seems to play a buffering role against the happiness aversion to depression relationship, namely, individuals reporting high and medium levels of hope evidenced a significantly weaker relationship between happiness aversion and depressive symptoms than individuals reporting low levels of hope.

\subsection{Clinical and Theoretical Implications}

Efforts to identify and change negative attitudes towards happiness are proposed within a number of schools of psychotherapy. For instance, during compassion-focused therapy, when an individual expresses fears about positive feelings, actions are urged to try to reduce these psychological barriers in order to achieve a successful therapeutic outcome (Gilbert, 2014). Hope therapy, in particular, has been clinically demonstrated to reduce levels of depression, anxiety and stress after intervention (Rahimipour, Shahghoian, \& Yazdani, 2015), and the present study highlights the important protective role that hope plays in relation to happiness aversion and depression. Research showing happiness aversion has direct links to depression motivates research such as the present study designed to identify potential third variables that can serve to blunt, buffer, and protect against the ill effects of happiness aversion. The current paper highlights the importance of hope in this regard, and the current findings reinforce the view that developing therapeutic, neuropsychological, and pharmacological interventions to alleviate happiness aversion in depressed clients will be useful (Ritsner, 2014a, 2014b).

The present findings suggest a role for considering positive psychology constructs, e.g. hope, within the broader context of clinical psychology. Typically, research surrounding mental wellbeing is focused on addressing negative correlates and sequelae of a particular psychological disorder, for instance, identifying negative self-schemas in individuals manifesting depression (Evans et al., 2005). However, effective clinical interventions may benefit from involving positive attributes that an individual may possess to assist them in times of psychological distress (Seligman \& Csikzentmihalyi, 2000). Recently, positive psychological interventions (PPIs) have been implemented and used within community samples and some of them have been empirically demonstrated to help promote psychological wellbeing. These positive interventions are based on theory and empirical evidence, and, overall, they have shown effectiveness in reducing depression with a medium effect size $(r=.31$; Sin \& Lyubomirsky, 2009). It has been discussed that the most reliable way to target happiness is by tackling strategies on an emotional and cognitive level as well as an individual's life circumstances. Previous interventions, for instance "Counting blessings" or the "Three good things" (Seligman, Steen, Park, \& Peterson, 2005), directly target and are designed to increase positive emotions. They additionally are developed 
to promote building techniques which self-generate positive emotions and regulate negative emotions. Previous interventions have focused on positive constructs, focusing specifically on hope alone (Feldman \& Dreher, 2012). As hope has been highlighted as playing a protective factor within this research, exploring how PPIs focused on hopeful attitudes contribute to reducing happiness aversion and depression is recommended for future research.

\subsection{Limitations and Suggestions for Future Research}

The current findings should be interpreted with caution. The main results were based on cross-sectional data, albeit with a large sample size, whereas the exploratory longitudinal analyses were based on a small sample. Causality cannot be attributed from analyses based on cross-sectional data (Jose, 2013a; MacKinnon, 2008), therefore the present findings need to be replicated with a more substantial longitudinal study. Also, future longitudinal studies should be based on larger, three-wave datasets as the additional time of measurement would enable a more sensitive analysis of temporal relationships (Jose, 2016). Additionally, although we found preliminary evidence that hope mediated between happiness aversion and depressive symptoms over time, it is highly likely that other attributes (both positive and negative) can be shown to mediate this relationship. And finally, experimental studies (e.g. an RCT study) are needed to show that interventions designed to reduce happiness aversion and/or boost hope would set in motion cascading effects to reduce persistent maladaptive mood states like depression.

\section{Conclusion}

The current research was carried out in order, first, to investigate the basic relationship between the happiness aversion and depression, and second, to examine the role of hope in the relationship between happiness aversion and depressive symptoms. Findings from both a large concurrent dataset as well as a small longitudinal dataset showed that hope moderated (buffered) and mediated the basic relationship in question. The findings suggest that positive dynamics such as hope have important implications for relationships between maladaptive constructs, and point out the potential importance of enhancing hope with interventions to disrupt the positive relationship between happiness aversion and depression.

\section{Conflicts of Interest}

On behalf of all authors, the corresponding author states that there is no conflict of interest.

\section{Data Availability}

The datasets generated during and/or analysed during the current study are available from the corresponding author on reasonable request. 


\section{References}

Abramson, L. Y., Metalsky, G. I., \& Alloy, L. B. (1989). Hopelessness Depression: A Theory-Based Subtype of Depression. Psychological Review, 96, 358-372. https://doi.org/10.1037/0033-295X.96.2.358

Agbo, A., \& Ngwu, C. (2017). Aversion to Happiness and the Experience of Happiness: The Moderating Roles of Personality. Personality and Individual Differences, 111, 227-231. https://doi.org/10.1016/j.paid.2017.02.010

Al-Modallal, H., Abuidhail, J., Sowan, A., \& Al-Rawashdeh, A. (2010). Determinants of Depressive Symptoms in Jordanian Working Women. Journal of Psychiatric and Mental Health Nursing, 17, 569-576. https://doi.org/10.1111/j.1365-2850.2010.01562.x

Arbuckle, J. L. (2013). Amos (Version 22.0). Computer Program. Chicago, IL: SPSS/IBM.

Arieti, S., \& Bemporad, J. R. (1980). The Psychological Organization of Depression. American Journal of Psychiatry, 137, 1360-1365. https://doi.org/10.1176/ajp.137.11.1360

Aristotle (1955). The Nicomachean Ethics. Translated by Thomson, J.A.K., London: Penguin.

Arnau, R., Rosen, D., Finch, J., Rhudy, J., \& Fortunato, V. (2007). Longitudinal Effects of Hope on Depression and Anxiety: A Latent Variable Analysis. Journal of Personality, 75, 43-64. https://doi.org/10.1111/j.1467-6494.2006.00432.x

Benjamin, D. J., Heffetz, O., Kimball, M. S., \& Rees-Jones, A. (2012). What Do You Think Would Make You Happier? What Do You Think You Would Choose? American Economic Review, 102, 2083-2110. https://doi.org/10.1257/aer.102.5.2083

Chang, E. C., \& Sanna, L. J. (2003). Optimism, Accumulated Life Stress, and Psychological and Physical Adjustment: Is It Always Adaptive to Expect the Best? Journal of Social and Clinical Psychology, 22, 97-115. https://doi.org/10.1521/jscp.22.1.97.22767

Chernoff, M., \& Chernoff, A. (2018). Getting Back to Happy. Los Angeles, CA: Tarcher Perigee.

Dichter, G. S. (2010). Anhedonia in Unipolar Major Depressive Disorder: A Review. The Open Psychiatry Journal, 4, 1-9. https://doi.org/10.2174/1874354401004010001

Diener, E. (2000). Subjective Well-Being: The Science of Happiness and a Proposal for a National Index. American Psychologist, 55, 34-43.

https://doi.org/10.1037//0003-066X.55.1.34

Du, H., King, R. B., \& Chu, S. K. W. (2016). Hope, Social Support, and Depression among Hong Kong Youth: Personal and Relational Self-Esteem as Mediators. Psychology, Health \& Medicine, 21, 926-931. https://doi.org/10.1080/13548506.2015.1127397

Evans, J., Heron, J., Lewis, G., Araya, R., \& Wolke, D. (2005). Negative Self-Schemas and the Onset of Depression in Women: A Longitudinal Study. The British Journal of Psychiatry, 186, 302-307. https://doi.org/10.1192/bjp.186.4.302

Feldman, D. B., \& Dreher, D. E. (2012). Can Hope Be Changed in 90 Minutes? Testing the Efficacy of a Single-Session Goal-Pursuit Intervention for College Students. Journal of Happiness Studies: An Interdisciplinary Forum on Subjective Well-Being, 13, 745-759. https://doi.org/10.1007/s10902-011-9292-4

Feldman, D. B., \& Snyder, C. R. (2005). Hope and the Meaningful Life: Theoretical and Empirical Associations between Goal-Directed Thinking and Life Meaning. Journal of Social and Clinical Psychology, 24, 401-421.

https://doi.org/10.1521/jscp.24.3.401.65616

Geiger, K. A., \& Kwon, P. (2010). Rumination and Depressive Symptoms: Evidence for 
the Moderating Role of Hope. Personality and Individual Differences, 49, 391-395. https://doi.org/10.1016/j.paid.2010.04.004

Gilbert, P. (2014). The Origins and Nature of Compassion-Focused Therapy. British Journal of Clinical Psychology, 53, 6-41. https://doi.org/10.1111/bjc.12043

Gilbert, P., McEwan, K., Gibbons, L., Chotai, S., Duarte, J., \& Matos, M. (2012). Fears of Compassion and Happiness in Relation to Alexithymia, Mindfulness, and Self-Criticism. Psychology and Psychotherapy: Theory, Research and Practice, 85, 374-390. https://doi.org/10.1111/j.2044-8341.2011.02046.x

Higgins, E. T. (2011). Beyond Pleasure and Pain: How Motivation Works. New York: Oxford University Press. https://doi.org/10.1017/CBO9780511527869.005

Horwitz, A. V., \& Wakefield, J. C. (2007). The Loss of Sadness: How Psychiatry Transformed Normal Sorrow into Depressive Disorder. Oxford: Oxford University Press.

Jansson-Boyd, C. V. (2010). Consumer Behaviour. New York: McGraw-Hill Education.

Jose, P. E. (2013a). Doing Statistical Mediation and Moderation. New York: Guilford Press.

Jose, P. E. (2013b). ModGraph-I: A Programme to Compute Cell Means for the Graphical Display of Moderational Analyses: The Internet Version, Version 3.0. Wellington: Victoria University of Wellington. https://psychology.victoria.ac.nz/modgraph

Jose, P. E. (2016). The Merits of Using Longitudinal Mediation. Educational Psychologist, 51, 331-341. https://doi.org/10.1080/00461520.2016.1207175

Jose, P. E., \& Huntsinger, C. S. (2005). Moderation and Mediation Effects of Coping by Chinese American and European American Adolescents. The Journal of Genetic Psychology, 166, 16-43. https://doi.org/10.3200/GNTP.166.1.16-44

Joshanloo, M. (2013). The Influence of Fear of Happiness Beliefs on Responses to the Satisfaction with Life Scale. Personality and Individual Differences, 54, 647-651. https://doi.org/10.1016/j.paid.2012.11.011

Joshanloo, M. (2018). Fear and Fragility of Happiness as Mediators of the Relationship between Insecure Attachment and Subjective Well-Being. Personality and Individual Differences, 123, 115-118. https://doi.org/10.1016/j.paid.2017.11.016

Joshanloo, M., \& Weijers, D. (2014). Aversion to Happiness across Cultures: A Review of Where and Why People Are Averse to Happiness. Journal of Happiness Studies, 15, 717-735. https://doi.org/10.1007/s10902-013-9489-9

Joshanloo, M., Lepshokova, Z. K., Panyusheva, T., Natalia, A., Poon, W. C., Yeung, V. W. L., Tsukamoto, S. et al. (2014). Cross-Cultural Validation of Fear of Happiness Scale across 14 National Groups. Journal of Cross-Cultural Psychology, 45, 246-264. https://doi.org/10.1177/0022022113505357

Joshanloo, M., Weijers, D., Jiang, D., Han, G., Bae, J., Pang, J., Natalia, A. et al. (2015). Fragility of Happiness Beliefs across 15 National Groups. Journal of Happiness Studies, 16, 1185-1210. https://doi.org/10.1177/0022022113505357

Layard, R. (2011). Happiness: Lessons from a New Science. London: Penguin. https://doi.org/10.1080/14733140600986227

Lin, T. H. (2010). A Comparison of Multiple Imputation with EM Algorithm and MCMC Method for Quality of Life Missing Data. Quality \& Quantity, 44, 277-287.

https://doi.org/10.1007/s11135-008-9196-5

MacKinnon, D. P. (2008). Introduction to Statistical Mediation Analysis. New York: Routledge. https://doi.org/10.4324/9780203809556

Mathew, J., Dunning, C., Coats, C., \& Whelan, T. (2014). The Mediating Influence of 
Hope on Multidimensional Perfectionism and Depression. Personality and Individual Differences, 70, 66-71. https://doi.org/10.1016/j.paid.2014.06.008

Maxwell, S. E., \& Cole, D. A. (2007). Bias in Cross-Sectional Analyses of Longitudinal Mediation. Psychological Methods, 12, 23-44.

https://doi.org/10.1037/1082-989X.12.1.23

Peterson, C. (2000). The Future of Optimism. American Psychologist, 55, 44-55. https://doi.org/10.1037/0003-066X.55.1.44

Quiggin, J. (1982). A Theory of Anticipated Utility. Journal of Economic Behavior and Organization, 3, 323-343. https://doi.org/10.1016/0167-2681(82)90008-7

Radloff, L. S. (1977). The CES-D Scale: A Self-Report Depression Scale for Research in the General Population. Applied Psychological Measurement, 1, 385-401. https://doi.org/10.1177/014662167700100306

Rahimipour, M., Shahgholian, N., \& Yazdani, M. (2015). Effect of Hope Therapy on Depression, Anxiety, and Stress among the Patients Undergoing Hemodialysis. Iranian Journal of Nursing and Midwifery Research, 20, 694-699. https://doi.org/10.4103/1735-9066.170007

Ritsner, M. S. (2014a). Anhedonia: A Comprehensive Handbook (Vol. I): Conceptual Issues and Neurobiological Advances. New York: Springer. https://doi.org/10.1007/978-94-017-8591-4

Ritsner, M. S. (2014b). Anhedonia: A Comprehensive Handbook (Vol. II): Neuropsychiatric and Physical Disorders. New York: Springer. https://doi.org/10.1007/978-94-017-8610-2

Rovner, B. W., \& Casten, R. J. (2001). Neuroticism Predicts Depression and Disability in Age-Related Macular Degeneration. Journal of the American Geriatrics Society, 8, 1097-1100. https://doi.org/10.1046/j.1532-5415.2001.49215.x

Rubin, A. M. (2009). Uses-and-Gratifications Perspective on Media Effects. In J. Bryant, \& M. B. Oliver (Eds.), Media Effects (pp. 181-200). New York: Routledge.

Seligman, M. E. P., \& Csikszentmihalyi, M. (2000). Positive Psychology: An Introduction. American Psychologist, 55, 5-14. https://doi.org/10.1037/0003-066X.55.1.5

Seligman, M. E. P., Steen, T. A., Park, N., \& Peterson, C. (2005). Positive Psychology Progress: Empirical Validation of Interventions. American Psychologist, 60, 410-421. https://doi.org/10.1037/0003-066X.60.5.410

Sin, N. L., \& Lyubomirsky, S. (2009). Enhancing Well-Being and Alleviating Depressive Symptoms with Positive Psychology Interventions: A Practice-Friendly Meta-Analysis. Journal of Clinical Psychology: In Session, 65, 467-487. https://doi.org/10.1002/jclp.20593

Snyder, C. R. (2000). Handbook of Hope: Theory, Measures, and Applications. San Diego, CA: Academic Press.

Snyder, C. R., Harris, C., Anderson, J. R., Holleran, S. A., Irving, L. M., Sigmon, S. T. et al. (1991). The Will and the Ways: Development and Validation of an Individual-Differences Measure of Hope. Journal of Personality and Social Psychology, 60, 570-585. https://doi.org/10.1037/0022-3514.60.4.570

Visser, P., Loess, P., Jeglic, E., \& Hirsch, J. (2013). Hope as a Moderator of Negative Life Events and Depressive Symptoms in a Diverse Sample: Stress and Health. Journal of the International Society for the Investigation of Stress, 29, 82-88.

https://doi.org/10.1002/smi.2433

Wigfield, A., \& Eccles, J. S. (2000). Expectancy-Value Theory of Achievement Motivation. Contemporary Educational Psychology, 25, 68-81.

https://doi.org/10.1006/ceps.1999.1015 